\title{
Integration of world-to-chip interfaces with digital microfluidics for bacterial transformation and enzymatic assays
}

\section{Supplementary Information}

Ehsan Moazami, ${ }^{1,2}$ James Perry, ${ }^{2,3}$ Guy Soffer, ${ }^{1,2}$ Mathieu C. Husser, ${ }^{2,3}$ Steve C.C. Shih ${ }^{1-3 *}$

${ }^{1}$ Department of Electrical and Computer Engineering, Concordia University, Montréal, Québec, Canada

${ }^{2}$ Centre for Applied Synthetic Biology, Concordia University, Montréal, Québec, Canada

${ }^{3}$ Department of Biology, Concordia University, Montréal, Québec, Canada

*Corresponding author

Tel: +1-(514)-848-2424 x7579

Email: steve.shih@ concordia.ca 


\section{Microfluidic device fabrication and operation}

Devices were designed using AutoCAD 2017 (Autodesk, San Rafael, CA) and fabricated in the

Concordia cleanroom. The DMF fabrication procedure followed a previous protocol ${ }^{1-2}$ using high resolution 25,400 dpi transparency masks printed by CAD/Art (Bandon, OR) services. Briefly, glass substrates pre-coated with S1811 photoresist (Telic, Valencia, CA) were exposed to UV for 8 s on a Quintel Q-4000 mask aligner (Neutronix Quintel, Morgan Hill, CA) to imprint the transparency masks design. These were developed in MF-321 for 2 min with shaking and rinsing with DI water. Developed slides were then baked at $115^{\circ} \mathrm{C}$ for $1 \mathrm{~min}$ before etching in CR-4 chromium etchant until the pattern was clearly visible. The remaining photoresist was then removed in AZ-300T stripper for 2 min. After rinsing with DI water and drying, a silane solution comprising de-ionized water, 2-propanol and (trimethoxysilyl)-propyl methacrylate (50:50:1 v/v) was added to the devices in a Pyrex dish for 15 min. Devices were primed for dielectric coating with $15 \mathrm{~g}$ of Parylene-C (7.2 $\mu \mathrm{m})$ in a SCS Labcoater 2 PDS 2010 (Specialty Coating Systems, Indianapolis, IN), and coated with Fluoropel PFC1601V (Cytonix, Beltsville, MD) in a Laurell spin coater (North Wales, PA) set to $1500 \mathrm{rpm}$ for $30 \mathrm{~s}$ with $500 \mathrm{rpm} / \mathrm{s}$ acceleration followed by 10 min baking at $180^{\circ} \mathrm{C}$.

Prior to experiments, two types of top-plates were prepared - ITO-DMF or ITO-well-DMF (Figure S3). ITO-DMF were coated with FluoroPel PFC $1601 \mathrm{~V}$ by spin coating and then postbaked as described above. For ITO-well-DMF, $1 \mathrm{~mm}$ diameter holes were drilled on the top plate using a Micromill (Proxxon MF 70, S.A. Wecker, Luxemburg) with a diamond drill bit (dia. 1.00 $\mathrm{mm}, \mathrm{L}=38 \mathrm{~mm}$, diamond tip length: $3.50 \mathrm{~mm}$, shank: $0.70 \mathrm{~mm}$; ordered from KLY Amazon). These were diced into $25 \mathrm{~mm}$ x $75 \mathrm{~mm}$ pieces and were coated with Fluoropel PFC1601V and post-baked using the conditions described above on both sides. A 3D-printed well (with $1 \mathrm{~mm}$ 
diameter holes; see Figure S2) that is coated inside with Fluoropel (using a cotton swab) were aligned directly on top of the holes on the ITO and glued (LePage super glue, Mississauga, Ontario) to the glass and dried for $5 \mathrm{~min}$ at room temperature. Both of these ITOs were joined to the bottom substrate with two pieces of double sided tape, resulting in an inter-plate gap of $\sim 140 \mu \mathrm{m}$.

A custom-designed fabricated device was used in this study for both bacterial transformation and enzymatic assay. After combining the top and bottom plates, the DMF device was primed to be interfaced through our automation system (see our online GitHub repository: [https://github.com/shihmicrolab/Automation]) that will automate the droplet movement on the devices. Electrodes were actuated using $160 \mathrm{~V}_{\mathrm{RMS}}$ at $15 \mathrm{kHz}$ using solid-state relays controlled by in-lab software.

\section{Competent cell preparation}

Prior to preparation, a $-80{ }^{\circ} \mathrm{C}$ freezer stock of $\mathrm{DH} 5 \alpha$ was streaked-out on a plate containing lysogeny Broth (LB) and 8\% agar and grown overnight (12 to $16 \mathrm{~h}$ ). On day 1, a single bacterial colony (2 to $3 \mathrm{~mm}$ in dia.) (from the streaked plate using the $-80{ }^{\circ} \mathrm{C}$ stock) was inoculated in $5 \mathrm{~mL}$ of $\mathrm{LB}$ in a $20 \mathrm{~mL}$ flask overnight (about 12 to $14 \mathrm{~h}$ ) at $37^{\circ} \mathrm{C}, 220 \mathrm{rpm}$. On day $2,6 \mathrm{~mL}$ of the culture was added into $600 \mathrm{~mL}$ of fresh LB medium and incubated in $37^{\circ} \mathrm{C}$ at $220 \mathrm{rpm}$. After 1.5 h, the OD 600 was measured every $15 \mathrm{~min}$ until the OD 600 level reached 0.45 . The cells were transferred to cold $50 \mathrm{~mL}$ centrifuge tubes. Before spinning, the centrifuge was spun for a few seconds to reach $4{ }^{\circ} \mathrm{C}$. Then the cells were recovered by centrifugation at $1000 \mathrm{~g}$ for $10 \mathrm{~min}$ at 4 ${ }^{\circ} \mathrm{C}$ after which the medium was decanted from the cell pellets. The bacterial sediment was resuspended in $50 \mathrm{~mL}$ of ice-cold solution containing $15 \%$ glycerol with $75 \mathrm{mM}$ of $\mathrm{CaCl}_{2}$ and was 
incubated on ice for $5 \mathrm{~min}$ and then centrifuged at $1000 \mathrm{~g}$ for $10 \mathrm{~min}$. After centrifugation, the cells were re-suspended in $2 \mathrm{~mL}$ of $75 \mathrm{mM} \mathrm{CaCl}_{2}$ with $15 \%$ glycerol solution. $100 \mu \mathrm{L}$ aliquots were snap frozen in liquid nitrogen and stored in $-80^{\circ} \mathrm{C}$ freezer.

\section{Cloning and Protein Expression}

The sequence for the Rhodothermus marinus SG0.5JP17-172 endoglucanase gene (EGL) was obtained from NCBI (GenBank accession number WP_014065767.1) and was synthesized by IDT (Coralville, IA) as a linear DNA fragment. The gene was amplified by PCR using Phusion polymerase (Thermo Fisher scientific, Waltham, MA) according to manufacturer's instructions (initial $98^{\circ} \mathrm{C}$ for $30 \mathrm{~s}, 98^{\circ} \mathrm{C}$ for $10 \mathrm{~s}, 55^{\circ} \mathrm{C}$ for $30 \mathrm{~s}, 72^{\circ} \mathrm{C}$ for $30 \mathrm{~s} / \mathrm{kb}$, final $72^{\circ} \mathrm{C}$ for $10 \mathrm{~min}$ and $4^{\circ} \mathrm{C}$ on hold, with 35 cycles of amplification). The following primers were used to introduce a 5' $\mathrm{XbaI}$ and a 3' BamHI restrictions sites:

Forward:

5'- TGACTGACTCTAGAAATAATTTTGTTTAACTTTAAGAAGGAGATATACC

ATGCGTGTATTGGCGCTGC - 3'

Reverse:

5' - GCATGCATGGATCCCTAATTGCGTGGATTTAATTGGCGC - 3'

The PCR product was purified, digested with $\mathrm{XbaI}$ and $\mathrm{BamHI}$ for two hours, and ligated into a linearized pET16b vector. The ligation product was transformed into chemically competent E.coli DH5 $\alpha$ cells and plated on selective media. Single colonies were inoculated in $5 \mathrm{~mL}$ of LB media 
containing $100 \mu \mathrm{g} / \mathrm{mL}$ ampicillin overnight and plasmids were extracted using a BioBasic miniprep kit. Proper insertion of the gene was verified by digesting $2 \mu \mathrm{g}$ of plasmid with XbaI and BamHI checking proper insert size on a $0.8 \%$ agarose gel. The cloned plasmid (pET_EGL) was transformed into E.coli BL21(DE3) for protein expression. The transformed cells were inoculated overnight in a $5 \mathrm{~mL}$ pre-culture. The next day, a $100 \mathrm{~mL}$ starter culture of low optical density (OD) was generated by diluting the overnight culture and grown at $37{ }^{\circ} \mathrm{C}$ with $200 \mathrm{rpm}$ shaking. Upon reaching OD 0.4, expression of the EGL gene was induced by addition of $1 \mathrm{mM}$ IPTG for 6 hours. The final induced culture was divided into $40 \mathrm{~mL}$ aliquots and centrifuged at $4000 \mathrm{rpm}$ for $5 \mathrm{~min}$. The pellets were frozen and kept at $-20{ }^{\circ} \mathrm{C}$ for later used. Thawed pellets were lysed at $4{ }^{\circ} \mathrm{C}$ for $15 \mathrm{~min}$ by resuspending in $10 \mathrm{~mL}$ of lysis solution comprising $1 \mathrm{mg} / \mathrm{mL}$ lysozyme, $25 \mathrm{U} / \mathrm{ml}$ benzonase and $1 \mathrm{mM}$ phenylmethanesulfonylfluoride (PMSF). The lysates were centrifuged again at $4000 \mathrm{rpm}$ for $5 \mathrm{~min}$ to collect the protein pellets. The pellets were resuspended in $10 \mathrm{~mL}$ of assay buffer (50 mM sodium-phosphate, $\mathrm{pH} 7.0)$ and diluted 50-fold in the same buffer before use. 
a)

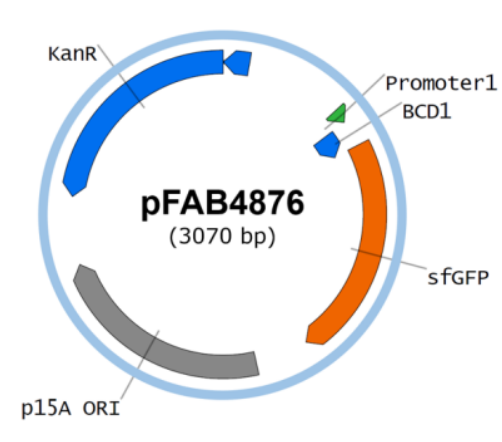

b)

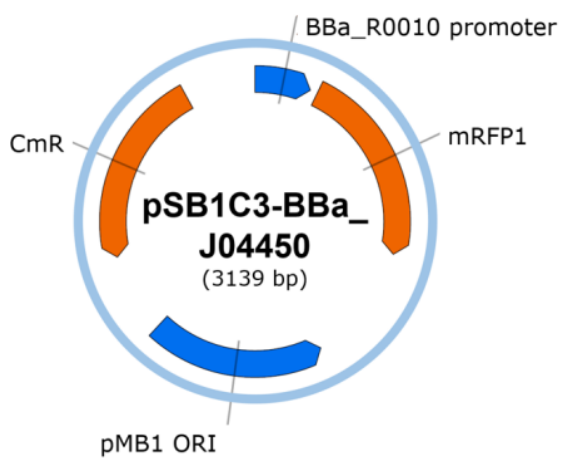

c)

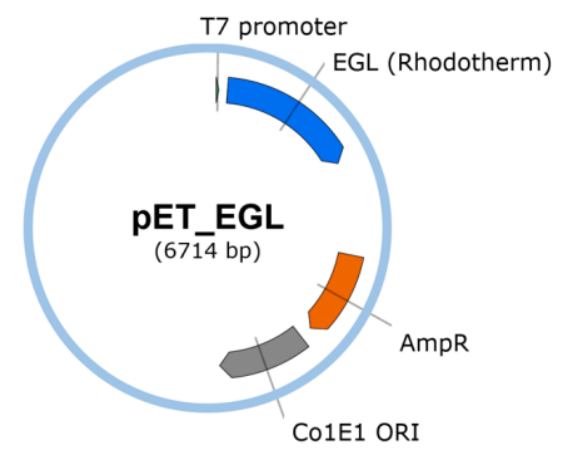

Figure S1 - Plasmid map of a) pFAB4876, b) pSB1C3, and c) pET-EGL. pFAB4876 and pSB1C3 were used for bacterial transformation and pET-EGL was used for the enzymatic assay. 

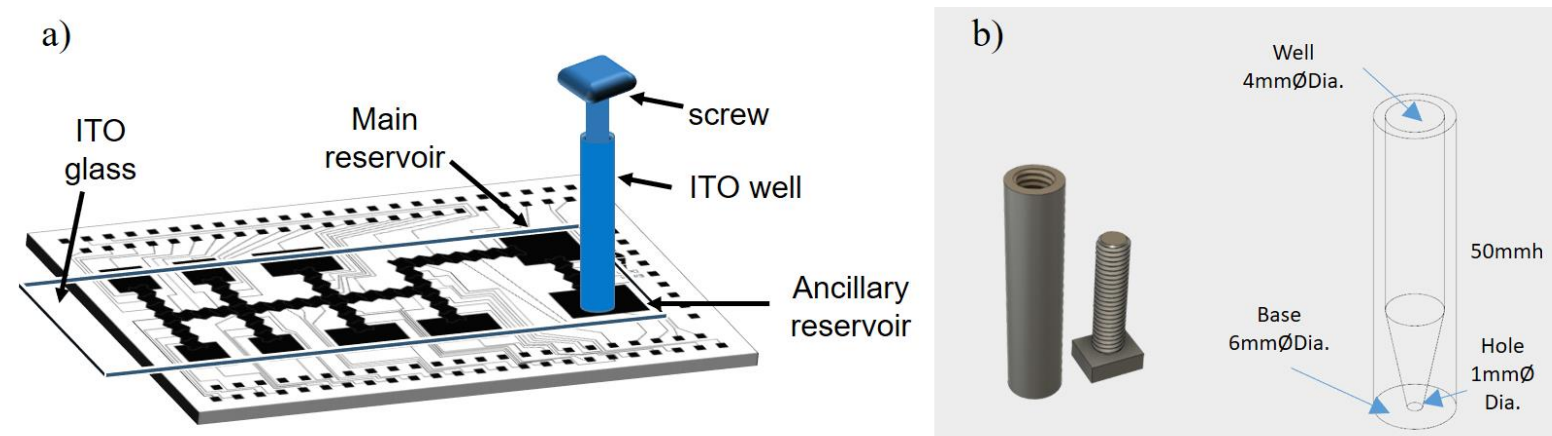

Figure S2 - Design and configuration of the 3D printed well. a) The configuration of the $3 D$ printed well on the DMF device. A plunger is added to the well to pressurize the liquid inside the well and to deliver the liquid into the ancillary reservoir. b) The design of the $3 D$ printed well. Inside is a conical design with the following dimensions as shown. 
a)

ITO-DMF

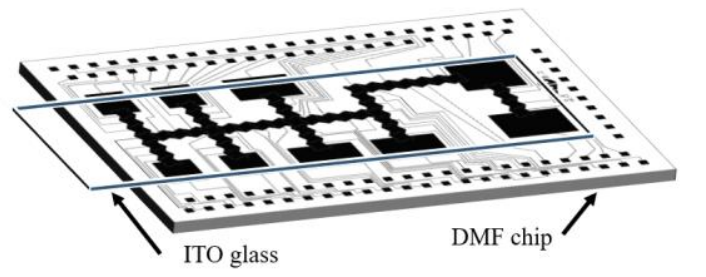

b)

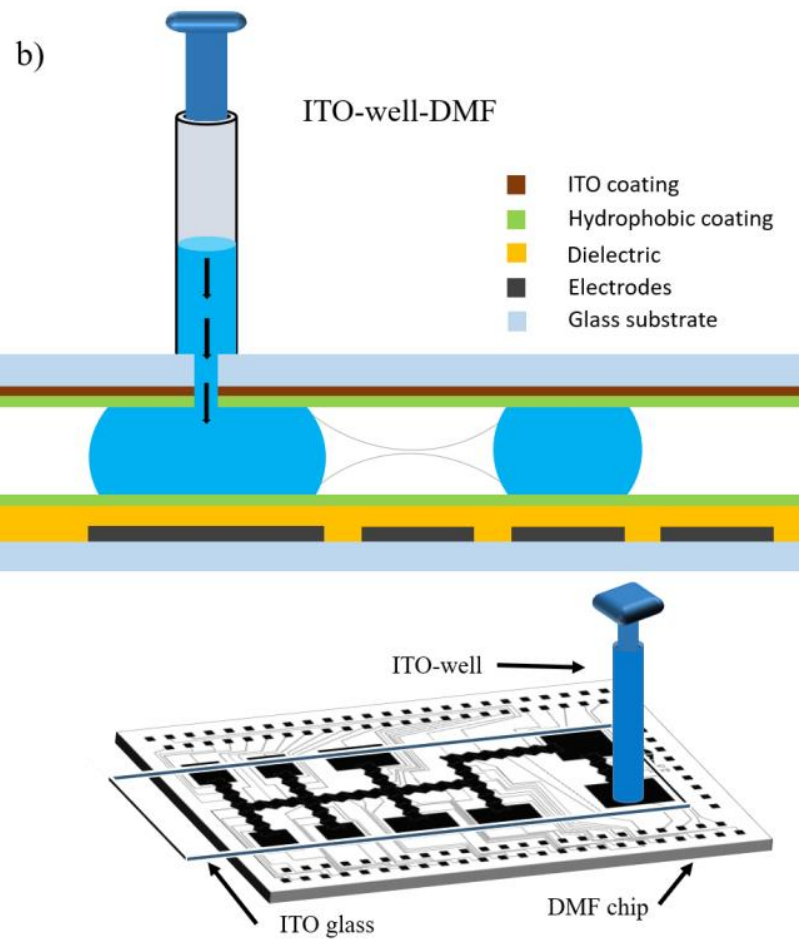

Figure S3 - Reagent delivery interface for digital microfluidic devices. a) ITO-DMF is the typical two-plate setup used for digital microfluidics to automate liquid handling on device. $b$ ) ITO-well-DMF is the new world-to-chip system for reagent delivery on device. It consists of a 3D printed well integrated on top of the ITO top-plate which is aligned to an electrode (i.e. reservoir) on the device. Approximately $400 \mu \mathrm{L}$ of liquid can be stored in the $3 D$ printed well. 
a)

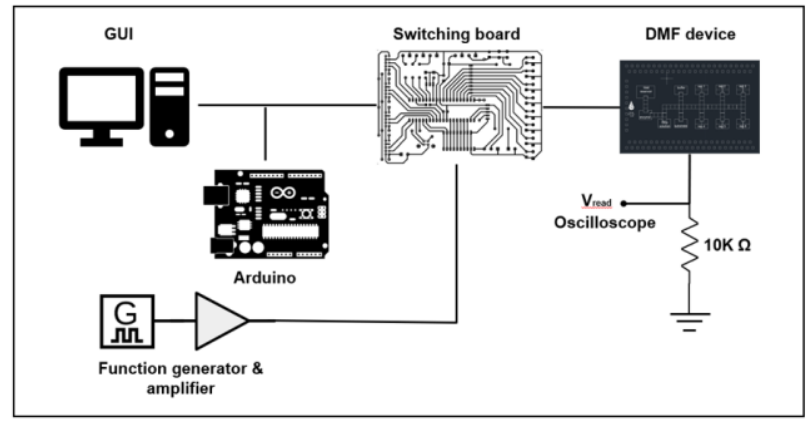

b)

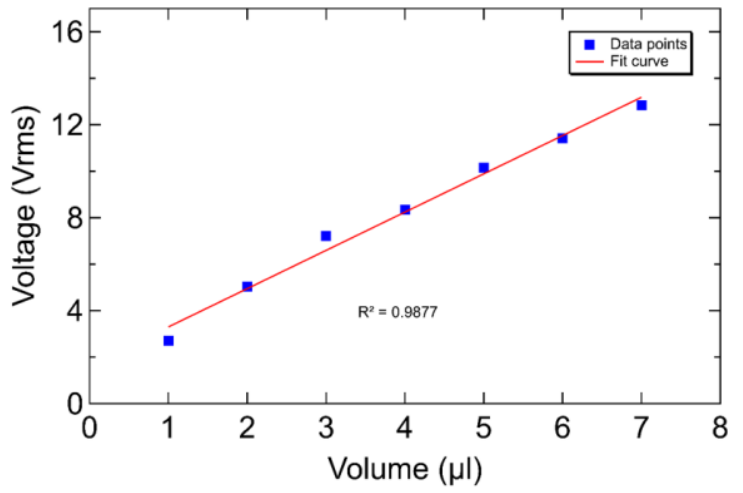

Figure S4 - Impedance measurement circuit to measure fluid volume on the device. (a) The circuit consists of a resistor and the potential $\left(V_{\text {read }}\right)$ is measured to correlate the amount of fluid to the potential. (b) Calibration curve to correlate volume and voltage. A droplet of specific volume was manually dispensed on the reservoir and the electrode was actuated using $160 V_{\text {rms. }}$ The measured voltage $\left(V_{\text {read }}\right)$ is the voltage drop across the resistor. This volume has a linear correlation with the voltage. Three replicates were used for each measurement. 
a)

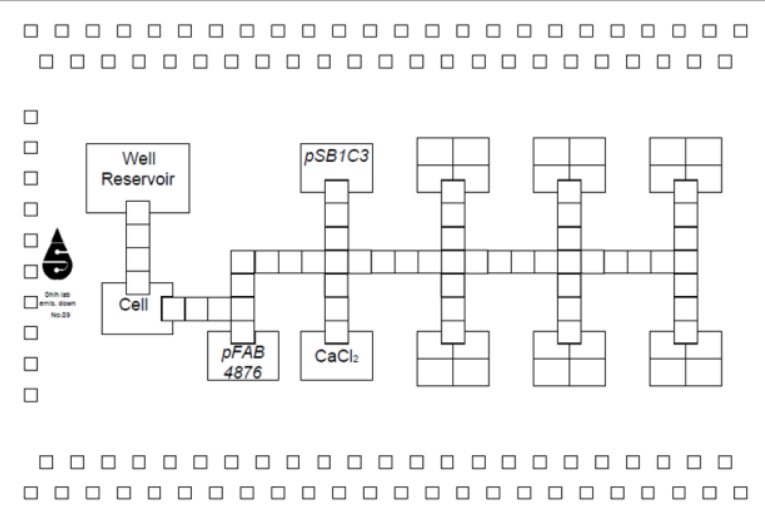

b)

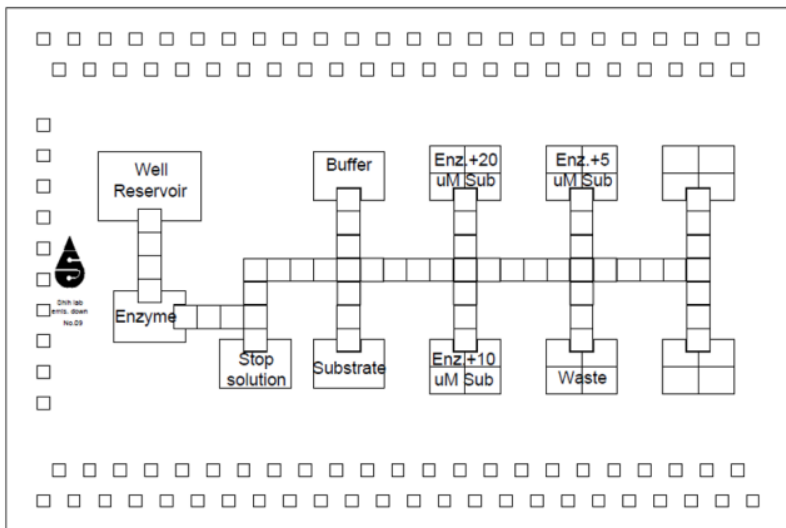

Figure S5 - DMF design layout for (a) bacterial transformation and (b) enzymatic assay experiments. 

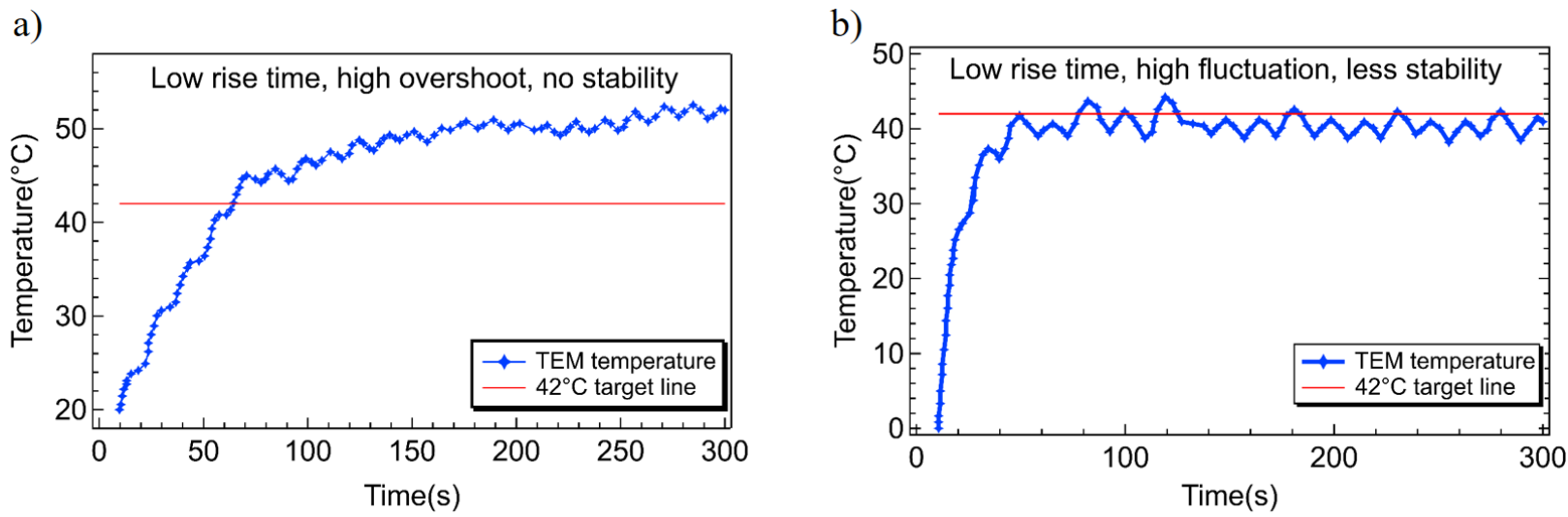

Figure S6 - Effects of closed-loop temperature control with non-optimal control parameters.

a) A graph shows the temperature output when the system is given a low rise time, high fluctuation, and low stability. b) A graph shows the temperature output when the system is given a low rise time, high overshoot, and no stability. All experiments had a target temperature of $42{ }^{\circ} \mathrm{C}$. 
Table S1: Description of strains and plasmids used in this study

\begin{tabular}{|c|c|c|}
\hline Strain or plasmid & Relevant genotype and description & Ref. or source \\
\hline \multicolumn{3}{|l|}{$\underline{\text { Strains }}$} \\
\hline E.coli $\mathrm{DH} 5 \alpha$ & $\begin{array}{l}\text { fhuA2 } \Delta(\operatorname{argF-lacZ}) \text { U169 phoA glnV44 } \Phi 80 \\
\Delta(\text { lacZ)M15 gyrA96 recA1 relA1 endA1 thi-1 } \\
\text { hsdR17 }\end{array}$ & $\begin{array}{l}\text { Vincent Martin Lab, } \\
\text { Concordia University }\end{array}$ \\
\hline E.coli BL21 & $\begin{array}{l}\text { F- ompT gal dem lon hsdSB(rB- mB-) } \lambda(\mathrm{DE} 3 \\
{[\text { lacI lacUV5-T7 gene } 1 \text { ind1 sam7 nin5]) }}\end{array}$ & $\begin{array}{l}\text { Vincent Martin Lab, } \\
\text { Concordia University }\end{array}$ \\
\hline \multicolumn{3}{|l|}{$\underline{\text { Plasmids }}$} \\
\hline & (origin, resistance, gene of interest?) & \\
\hline pFAB 4876 & DH5 $\alpha$, Kanamycin, GFP & $\begin{array}{l}\text { Vincent Martin Lab, } \\
\text { Concordia University }\end{array}$ \\
\hline pSB1C3 & DH5 $\alpha$, Chloramphenicol, RFP & $\begin{array}{l}\text { Vincent Martin Lab, } \\
\text { Concordia University }\end{array}$ \\
\hline pET-EGL & BL21 (DE3), Ampicillin, EGL & This study \\
\hline
\end{tabular}


Table S2 - Equations and parameters used to model the closed-loop thermoelectric cooler.

\begin{tabular}{|c|c|c|}
\hline Process & Equation & Parameter \\
\hline Thermal conduction & $\boldsymbol{Q}_{t h}=-\Delta \boldsymbol{T} * K_{t h}$ & $\begin{array}{l}K_{t h}: \text { Thermal conductivity coefficient } \\
\text { of TEC }=0.39\end{array}$ \\
\hline Joule heating & $Q_{j}=I^{2} R$ & $\begin{array}{l}\text { R: } \text { TEC internal resistance }=1.4 \Omega \\
I: \text { drawn current }\end{array}$ \\
\hline $\begin{array}{c}\text { Peltier } \\
\text { cooling/heating }\end{array}$ & $\begin{aligned} Q_{p a} & =S_{m} * I * T_{h} \\
Q_{p e} & =S_{m} * I * T_{c}\end{aligned}$ & 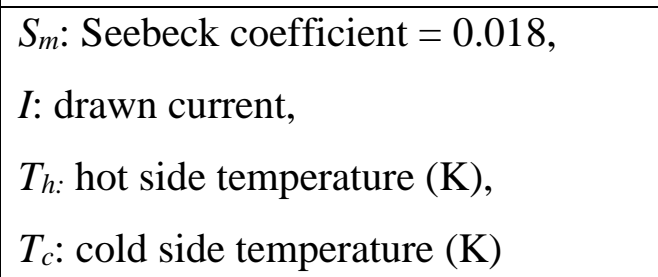 \\
\hline Seebeck & $V_{s}=S_{m} * \Delta T\left(T_{h}-T_{c}\right)$ & $\begin{array}{l}S_{m}: \text { Seebeck coefficient }=0.018, \\
T_{h:} \text { hot side temperature }(\mathrm{K}), \\
T_{c}: \text { cold side temperature }(\mathrm{K})\end{array}$ \\
\hline $\begin{array}{c}\text { Heat transfer } \\
\text { equation in TEC }\end{array}$ & $\begin{aligned} Q_{t a} & =Q_{p a}-0.5 Q_{j}-Q_{t h} \\
Q_{t e} & =Q_{p e}+0.5 Q_{j}-Q_{t h}\end{aligned}$ & $\begin{array}{l}Q_{p a}: \text { Peltier heating, } \\
Q_{t a}: \text { Peltier cooling, } \\
Q_{t h}: \text { Thermal conduction, }\end{array}$ \\
\hline $\begin{array}{l}\text { Aluminum heat } \\
\text { block temperature }\end{array}$ & $T_{h}=\frac{\int\left(\left(T_{a m b} * K_{t h}\right)+Q_{t e}\right)}{\text { Alum. thermal mass }}$ & $\begin{array}{l}Q_{t e}: \text { total heat transfer (hot side), } \\
K_{t h}: \quad \text { thermal } \quad \text { conductivity of } \\
\text { Aluminum }=0.03, \\
T_{a m b}: \text { room temperature in }{ }^{\circ} \mathrm{C}, \\
\text { Aluminum thermal mass }=12.776\end{array}$ \\
\hline $\begin{array}{c}\text { Heat sink block } \\
\text { temperature }\end{array}$ & $T_{c}=\frac{\int\left(\left(T_{a m b} * K_{t h}\right)+Q_{t a}\right)}{\text { Heatsink thermal mass }}$ & $\begin{array}{l}Q_{t a}: \text { total heat transfer (cold side), } \\
K_{t h:}: \text { thermal conductivity of metal }= \\
10, \\
\text { Heatsink thermal mass }=200\end{array}$ \\
\hline
\end{tabular}


Table S3 - Comparison of "world-to-chip" interfaces on DMF and our work

\begin{tabular}{|c|c|c|}
\hline Property & Current literature & Our work \\
\hline Reagent Delivery & $\begin{array}{l}\text { Use of pressure sources and } \\
\text { external moving parts to } \\
\text { deliver liquid } \\
\text { No refilling in reservoirs } \\
\text { Typical volumes } \sim 1-2 \mu \mathrm{L} \\
\text { References: }{ }^{3-6}\end{array}$ & $\begin{array}{l}\text { No external pressure sources, } \\
\text { only a plunger mated to a 3D } \\
\text { printed well } \\
\text { Refill reservoirs after every } \\
\text { dispensing action resulting in } \\
\text { reproducible dispensing } \\
\text { Can store at least } 400 \mu \mathrm{L} \text { of } \\
\text { volume in the well }\end{array}$ \\
\hline Temperature Control & $\begin{array}{l}\text { Off-chip heating } \\
\text { Directly fabricate electrode } \\
\text { heaters on device } \\
\text {-9 } 9 \\
\text { Open-loop control }{ }^{10}-\text { no } \\
\text { tuning or simulation provided }^{2,7}\end{array}$ & $\begin{array}{l}\text { On-chip heating and cooling } \\
\text { Interfacing TEC directly } \\
\text { below device - no extra } \\
\text { fabrication needed } \\
\text { Closed-loop control with } \\
\text { modeling of the system } \\
\text { enabling rapid changes in } \\
\text { temperature }\end{array}$ \\
\hline
\end{tabular}

\section{References:}

1. Sinha, H.; Quach, A. B. V.; Vo, P. Q. N.; Shih, S. C. C., An automated microfluidic geneediting platform for deciphering cancer genes. Lab Chip 2018, 18, 2300-2312.

2. Husser, M.; Vo, P. Q. N.; Sinha, H.; Ahmadi, F.; Shih, S. C. C., An automated induction microfluidics system for synthetic biology. ACS Synth. Biol. 2018, 7, 933-944.

3. Kim, H.; Bartsch, M. S.; Renzi, R. F.; He, J.; Van de Vreugde, J. L.; Claudnic, M. R.; Patel, K. D., Automated digital microfluidic sample preparation for next-generation DNA sequencing. $J$ Lab Autom 2011, 16 (6), 405-14.

4. Jebrail, M. J.; Sinha, A.; Vellucci, S.; Renzi, R. F.; Ambriz, C.; Gondhalekar, C.; Schoeniger, J. S.; Patel, K. D.; Branda, S. S., World-to-digital-microfluidic interface enabling extraction and purification of RNA from human whole blood. Anal Chem 2014, 86 (8), 3856-62.

5. Jebrail, M. J.; Renzi, R. F.; Sinha, A.; Van De Vreugde, J.; Gondhalekar, C.; Ambriz, C.; Meagher, R. J.; Branda, S. S., A solvent replenishment solution for managing evaporation of biochemical reactions in air-matrix digital microfluidics devices. Lab Chip 2015, 15 (1), 151-8.

6. Shah, G. J.; Ding, H.; Sadeghi, S.; Chen, S.; Kim, C. J.; van Dam, R. M., On-demand droplet loading for automated organic chemistry on digital microfluidics. Lab Chip 2013, 13 (14), 2785-95.

7. Au, S. H.; Shih, S. C. C.; Wheeler, A. R., Integrated microbioreactor for culture and analysis of bacteria, algae and yeast. Biomed. Microdevices 2011, 13 (1), 41-50. 
8. Shilton, R. J.; Travagliati, M.; Beltram, F.; Cecchini, M., Nanoliter-droplet acoustic streaming via ultra high frequency surface acoustic waves. Adv Mater 2014, 26 (29), 4941-6.

9. Prakash, R.; Pabbaraju, K.; Wong, S.; Wong, A.; Tellier, R.; Kaler, K. V. I. S., Multiplex, Quantitative, Reverse Transcription PCR Detection of Influenza Viruses Using Droplet Microfluidic Technology. Micromachines 2015, 6 (1), 63-79.

10. Gach, P. C.; Shih, S. C. C.; Sustarich, J.; Keasling, J. D.; Hillson, N. J.; Adams, P. D.; Singh, A. K., A Droplet Microfluidic Platform for Automating Genetic Engineering. ACS Synth. Biol. 2016, 5 (5), 426-33.

11. Tsai, H.-L.; Lin, J.-M., Model Building and Simulation of Thermoelectric Module Using Matlab/Simulink. Journal of Electronic Materials 2009, 39 (9), 2105-2111. 


\section{Thermal Plant}

To simulate a closed-loop system, I modeled the PID controller using the equations shown below. The thermal plant was modeled as a thermodynamic system (similar to ref ${ }^{77}$ ) consisting of two components: the thermoelectric module (TEM) and heat block modules. The TEM has the form of thermopiles that are connected electrically in series to increase the operating voltage and thermally in parallel to decrease the thermal resistance. It is also sandwiched between two ceramic plates for uniform thermal expansion. There are four main energy processes taking place in the TEM pellets:

- Thermal conductivity

- Joule heating

- The Peltier cooling/heating effect and

- $\quad$ The Seebeck effect

\section{Thermoelectric module (TEM) Simulink simulation}

\section{(a) Thermal conductivity}

The phenomenon of thermal conduction is a Fourier process that is described by the thermal conductivity $\mathrm{K}_{\mathrm{i}}$ of the material. Both ceramic plates and interconnected metals have high thermal conductivity to ensure uniform temperature at either end. Neglecting the contribution of the metal interconnectors and ceramic plates, the analysis of a TEM can be conducted by analyzing a single pellet or thermocouple without loss of generality. Hence the analysis of $\mathrm{N}$ thermocouple 
is the same as analysis of one thermocouple, the heat transfer of thermal conduction is described by:

$$
Q_{t h}=-\Delta T \times K_{t h}
$$

where $\mathrm{K}_{\mathrm{th}}$ is thermal conductivity coefficient

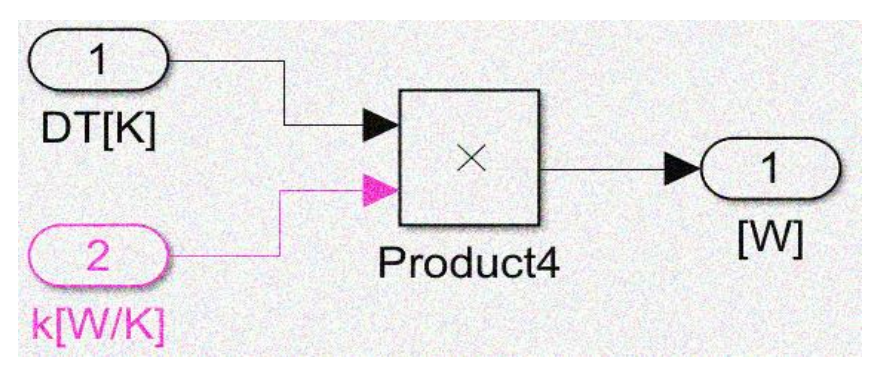

\section{(b) Joule heating}

Joule heating is a physical process of heat dissipation in a resistance element. The flow of electric current through the TEM will additionally cause resistive heating of the thermocouples. The total Joule heat dissipated in TEM is:

$$
Q_{j}=I^{2} R
$$

where $\mathrm{R}$ is the TEC internal resistance, $\mathrm{I}$, is current drawn from DC power supply, and $\mathrm{Q}_{\mathrm{j}}$ is the calculated power (heat produced by passing current). Irrespective of the temperature gradient, Joule heating can be considered as equally divided between the two sides of the TEM. 


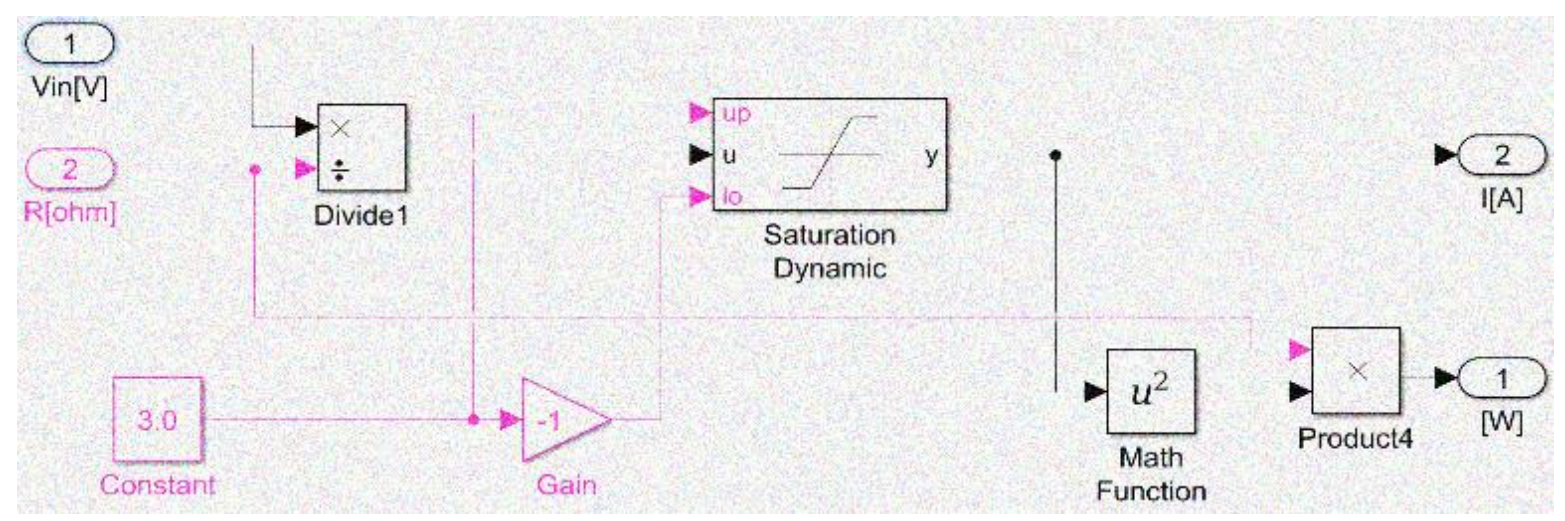

\section{(c) Peltier cooling/heating effect}

The Peltier cooling/heat effect is a phenomenon of heat absorption/dissipation by a junction between two dissimilar materials when electrical current flows through the junction. The absorbed/emitted heat of an N-couple TEM is:

$$
\begin{aligned}
& Q_{p a}=S_{m} * I * T_{h} \\
& Q_{p e}=S_{m} * I * T_{c}
\end{aligned}
$$

where $S_{m}$ is the Seebeck coefficient, $I$, is the current drawn from DC power supply, $T_{h}$ is the hot side temperature in Kelvin, $\mathrm{T}_{\mathrm{c}}$ is the cold side temperature in Kelvin, $\mathrm{Q}$ is the calculated power (heat produced by passing current). For calculation of emitted heat, the cold side temperature should be used and for the absorbed heat, the hot side temperature should be used. 


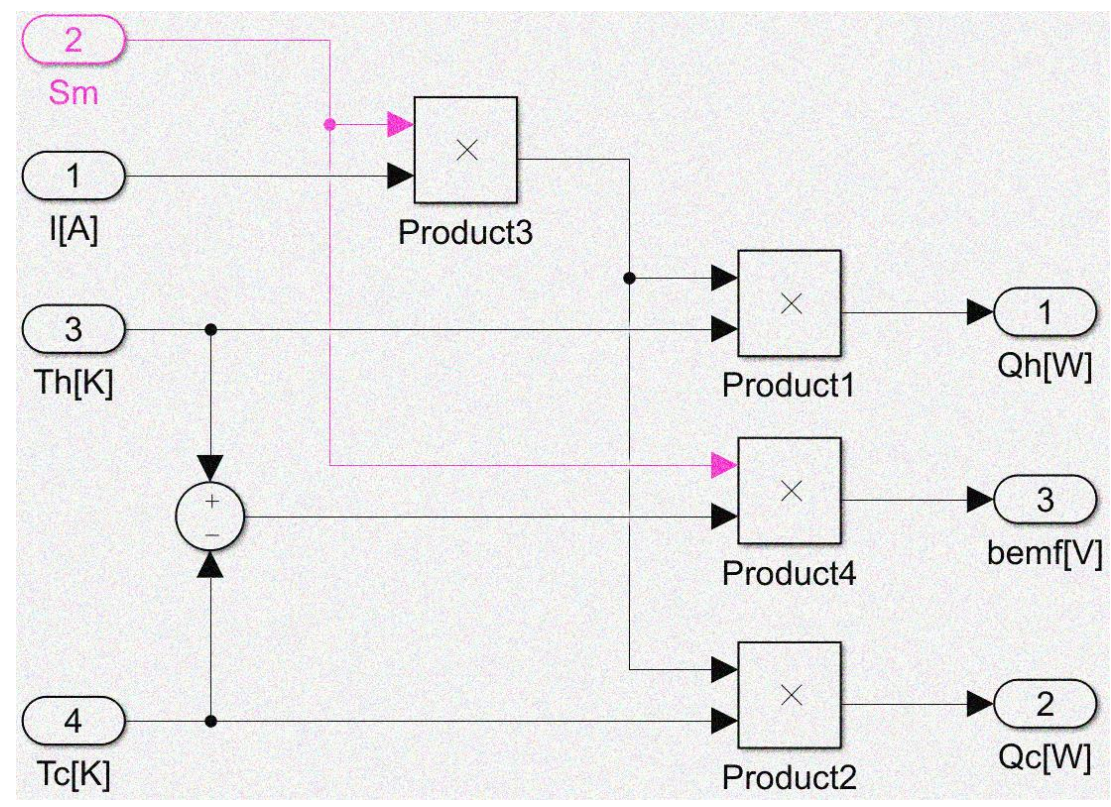

\section{(d) Seebeck effect}

When a temperature gradient is imposed on a conductor under an open-circuit condition, the creation of an electrical potential difference between the hot and cool sides of the conductor is called the Seebeck effect. The generated Seebeck voltage, called the back electromotive force (BEMF), in a TEM is expressed as:

$$
V_{s}=S_{m} * \Delta T
$$

where $S_{\mathrm{m}}$ is the Seebeck coefficient. Now the total heat transfer at two side of Peltier equals to:

$$
\begin{aligned}
& Q_{t a}=Q_{p a}-0.5 Q_{j}-Q_{t h} \\
& Q_{t e}=Q_{p e}+0.5 Q_{j}-Q_{t h}
\end{aligned}
$$




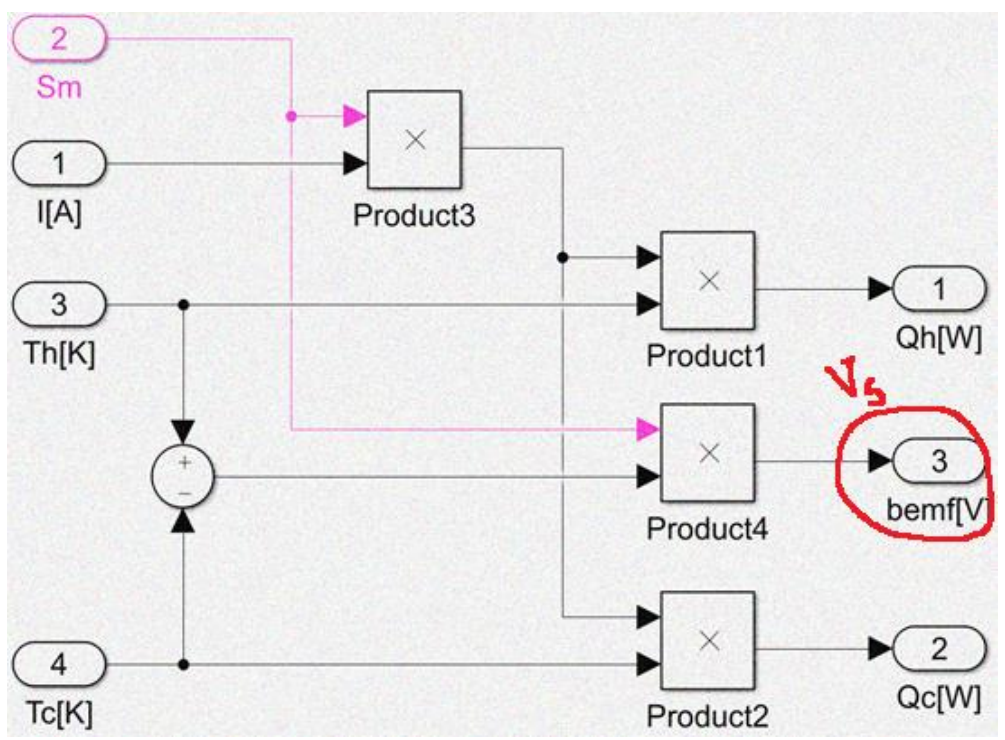

The Peltier output voltage is:

$$
V_{t}=V_{s}+I R
$$

Heat-block/heat-sink module Simulink simulation

\section{(a) Aluminum heat block temperature}

The temperature of Aluminum heat block connected to the glass chip, which our temperature sensor also fitted in, is calculated as follows:

$$
T_{h}=\frac{\int\left(\left(T_{a m b} * K_{t h}\right)+Q_{t e}\right)}{\text { Alum. thermal mass }}
$$

where $\mathrm{Q}_{\mathrm{te}}$ is the total heat transfer in the hot side calculated in TEM, $\mathrm{K}_{\mathrm{th}}$ is the thermal conductivity of Aluminum, $\mathrm{T}_{\mathrm{amb}}$ is the room temperature in ${ }^{\circ} \mathrm{C}$, and thermal mass can be calculated based on the heat block dimension and thermal capacity coefficient. 


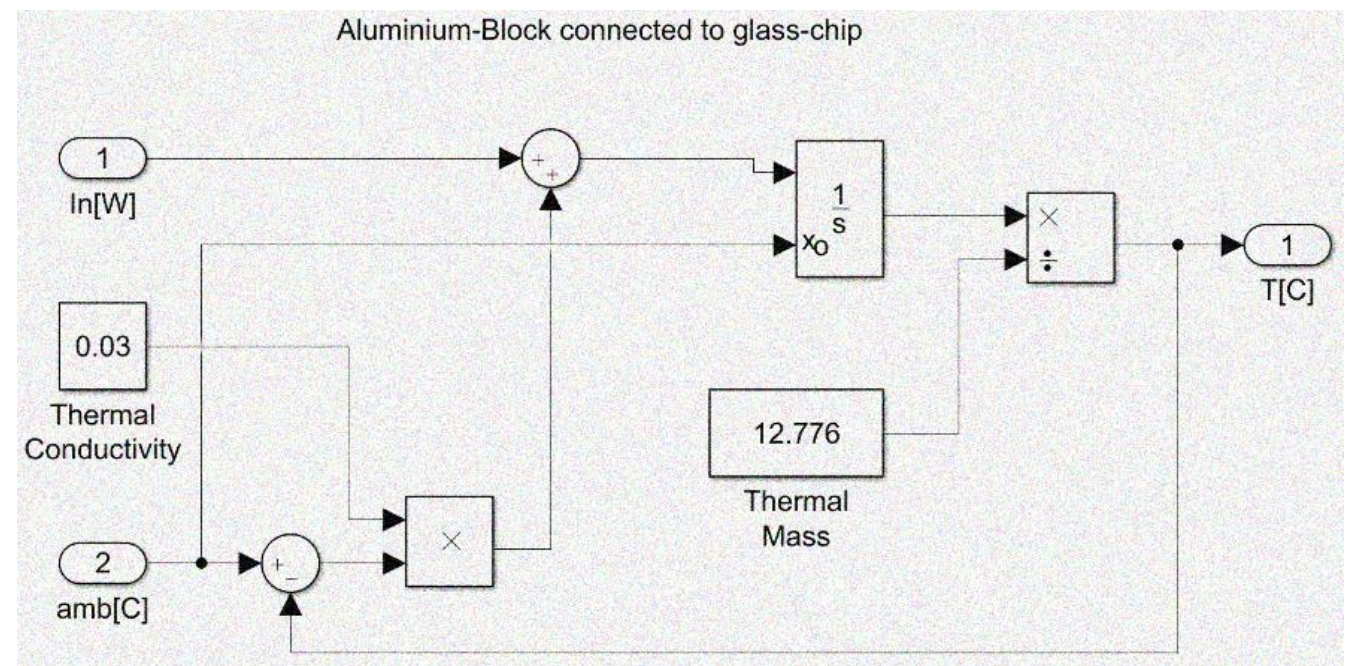

\section{(b) Heatsink block temperature}

The temperature of heatsink block connected to the fan is calculated as follows:

$$
T_{c}=\frac{\int\left(\left(T_{a m b} * K_{t h}\right)+Q_{t a}\right)}{\text { Heatsink thermal mass }}
$$

where $\mathrm{Q}_{\mathrm{ta}}$ is the total heat transfer in cold side calculated in TEC, $\mathrm{K}_{\mathrm{th}}$ is the thermal conductivity of metal, $\mathrm{T}_{\mathrm{amb}}$ is the room temperature in ${ }^{\circ} \mathrm{C}$, and Heatsink thermal mass can be calculated easily for the heatsink. 


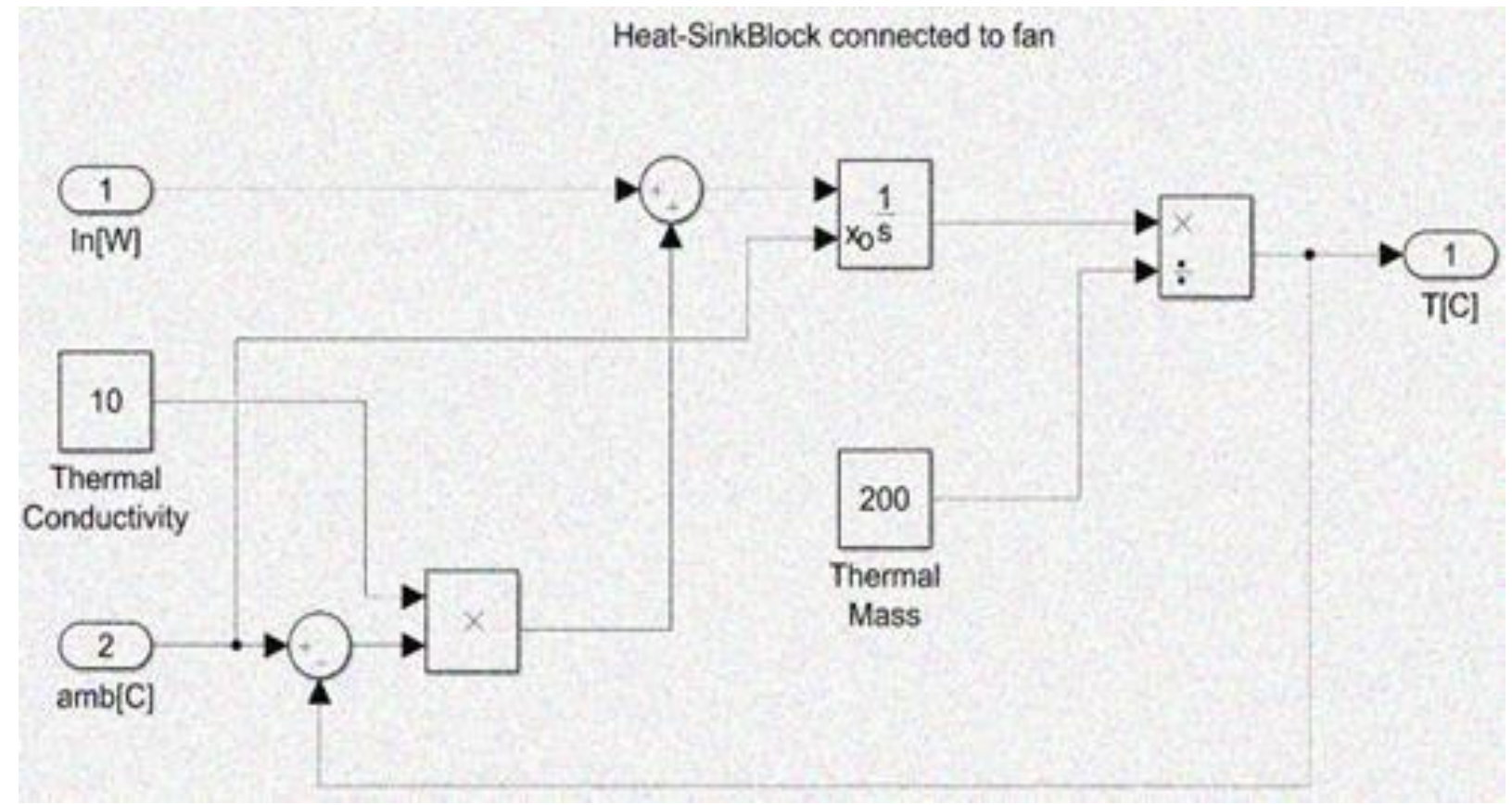

The aluminum thermal mass is used to calculate the thermal capacity of the aluminum block. 


\section{Calculation of thermal capacity of an aluminium block}

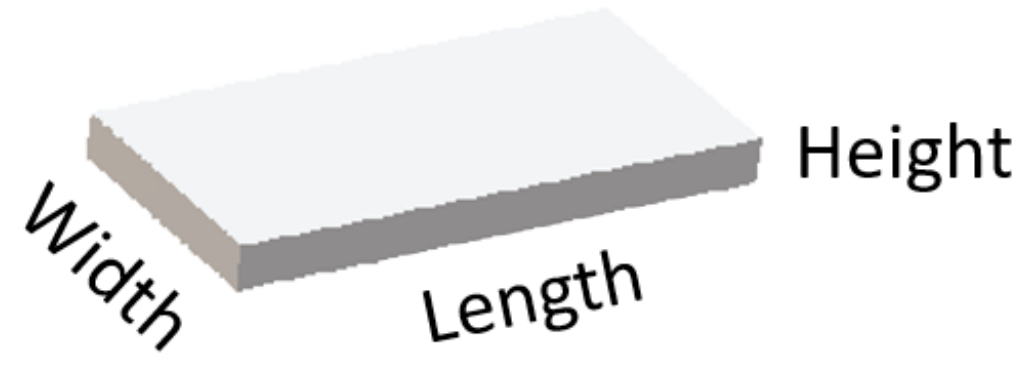

Parameters:

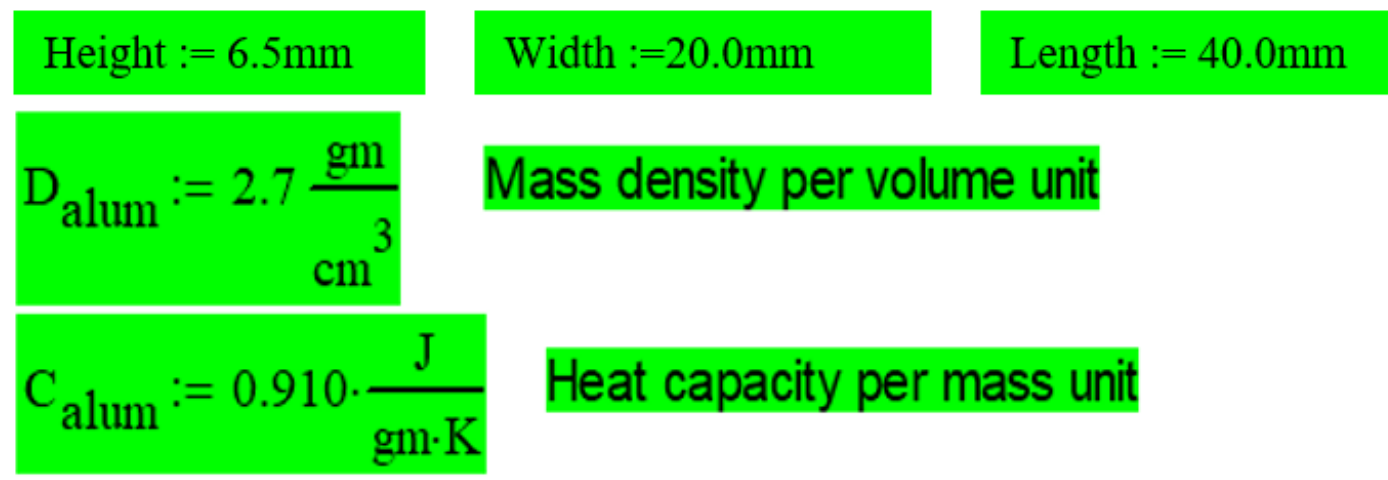

Calculation:

$\mathrm{M}:=$ Height.Width.Length. $\mathrm{D}_{\text {alum }}=14.04 \mathrm{gm}$

ThermalCapacity $:=\mathrm{M} \cdot \mathrm{C}_{\text {alum }}=12.776 \frac{\mathrm{m}^{2} \cdot \mathrm{kg}}{\mathrm{K} \cdot \mathrm{s}^{2}}$

$\mathrm{E}_{\text {alum }}(\Delta \mathrm{T}):=$ ThermalCapacity. $\Delta \mathrm{T}$

$\mathrm{E}_{\text {alum }}(1 \mathrm{~K})=12.776 \mathrm{~s} \cdot \mathrm{W}$ 